\title{
Ribosomal stalling landscapes revealed by high-throughput inverse toeprinting of mRNA libraries
}

\author{
Britta Seip (1), Guénaël Sacheau, Denis Dupuy (1), C Axel Innis (1)
}

\begin{abstract}
Although it is known that the amino acid sequence of a nascent polypeptide can impact its rate of translation, dedicated tools to systematically investigate this process are lacking. Here, we present high-throughput inverse toeprinting, a method to identify peptide-encoding transcripts that induce ribosomal stalling in vitro. Unlike ribosome profiling, inverse toeprinting protects the entire coding region upstream of a stalled ribosome, making it possible to work with random or focused transcript libraries that efficiently sample the sequence space. We used inverse toeprinting to characterize the stalling landscapes of free and drug-bound Escherichia coli ribosomes, obtaining a comprehensive list of arrest motifs that were validated in vivo, along with a quantitative measure of their pause strength. Thanks to the modest sequencing depth and small amounts of material required, inverse toeprinting provides a highly scalable and versatile tool to study sequencedependent translational processes.
\end{abstract}

DOI 10.26508/Isa.201800148 | Received 7 August 2018 | Revised 25 September 2018 | Accepted 27 September 2018 | Published online 9 October 2018

\section{Introduction}

Multiple factors determine the rate at which a nascent polypeptide is synthesized by the ribosome, among which is its amino acid sequence (Ito, 2014). Striking examples of translation regulation by the nascent chain are arrest peptides, a diverse class of regulators sharing a common propensity to block the ribosomes responsible for producing them (Wilson \& Beckmann, 2011; Ito \& Chiba, 2013; Wilson et al, 2016). In some cases, ribosome inhibition requires increased levels of a specific metabolite or drug, with the arrest peptide and ribosome acting as a combined sensor for these small molecules (Ramu et al, 2009; Vázquez-Laslop et al, 2011). More generally, simple features such as stretches of positively charged residues or prolinerich motifs can induce pauses in translation (Lu \& Deutsch, 2008; Peil et al, 2013; Woolstenhulme et al, 2013; Qi et al, 2018). Ribosometargeting antibiotics, such as macrolides, phenicols, or oxazolidinones, also slow down the translation of short problematic amino acid motifs (Arenz et al, 2014; Davis et al, 2014; Kannan et al, 2014; Marks et al, 2016; Ramu et al, 2009; Vázquez-Laslop et al, 2010).

Ribosomal stalling on the mRNA induced by nascent peptides can impact processes such as co-translational protein folding or secretion (Nakatogawa \& Ito, 2001; Chiba et al, 2009), mRNA degradation (Chiba et al, 1999; Chiba et al, 2003), or the expression of neighboring ORFs on the same transcript (Ito \& Chiba, 2013; Wilson et al, 2016). Although the true impact of the nascent amino acid sequence on gene expression remains unknown, the large number of translated upstream ORFs discovered in recent years suggests that peptide-induced ribosomal stalling could represent a widespread form of translational control (Andrews \& Rothnagel, 2014; Storz et al, 2014; Seip \& Innis, 2016; Ndah et al, 2017). Moreover, understanding the link between the sequence-dependence of antibiotics and their efficacy as ribosomal inhibitors could help pinpoint the most promising lead compounds for further development. This is particularly true for macrolide antibiotics, which have seen a resurgence following the introduction of a total synthesis approach allowing the production of a virtually endless number of derivatives (Seiple et al, 2016; Dinos, 2017). Thus, efforts are needed to systematically investigate the complex interplay between nascent amino acid sequences and the rate at which they are synthesized under different environments.

At present, ribosome profiling (Ingolia et al, 2009) is the main tool capable of providing a global in vivo view of ribosome density on the mRNA, which can be used as a proxy for measuring sequencedependent translation inhibition. Ribosome profiling has been used to study the translational pausing landscape in bacteria lacking the rescue factor elongation factor $\mathrm{P}(\mathrm{EF}-\mathrm{P})$ (Woolstenhulme et al, 2015) and to identify nascent amino acid motifs responsible for antibiotic-dependent translational arrest in the Gram-negative bacterium Escherichia coli (Kannan et al, 2014) and in the Gram-positive bacterium Staphylococcus aureus (Davis et al, 2014). Ribosomeprotected mRNA footprints obtained by ribosome profiling are short and encode only a few amino acids upstream of the pause site (Woolstenhulme et al, 2015; Mohammad et al, 2016). This means that information concerning the nascent peptide's amino acid sequence must be inferred from the mapping of ribosome footprints to a reference genome. Consequently, ribosome profiling cannot be used on a pool of uncharacterized coding sequences, as might be found in

Institut Européen de Chimie et Biologie, Université de Bordeaux, Institut National de la Santé et de la Recherche Médicale and Centre National de la Recherche Scientifique, Pessac, France

Correspondence: axel.innis@inserm.fr; denis.dupuy@inserm.fr 
a hypothetical Systematic Evolution of Ligands by Exponential Enrichment (SELEX)-type experiment (Ellington \& Szostak, 1990; Tuerk \& Gold, 1990) seeking to identify a novel metabolite-dependent arrest peptide. A couple of genetic selection techniques in bacteria have sought to overcome this drawback, but they are limited in scope (Tanner et al, 2009; Woolstenhulme et al, 2013). In addition, the bacterial culture volumes and sequencing depth necessary to perform ribosome profiling are incompatible with the systematic screening of potential antibiotic leads or small molecules likely to act as coinducers of arrest. To overcome these limitations, we developed a new, highly scalable in vitro method to investigate ribosomal stalling by nascent peptides encoded within transcript libraries of any given complexity.

Inverse toeprinting is a versatile selection strategy that relies on a highly processive $3^{\prime}$ to $5^{\prime}$ RNA exonuclease to degrade the mRNA downstream of the leading ribosome on a transcript. This makes it possible to determine the position of stalled ribosomes on the mRNA with codon resolution, while protecting the entire upstream peptide-encoding region. Inverse toeprinting is amenable to highthroughput, as next-generation sequencing can be used as readout. Because it is an in vitro method, it allows the precise control of translation conditions and can further be incorporated into selection schemes tailored to a variety of applications. We used inverse toeprinting to explore the stalling landscapes of free and drug-bound bacterial ribosomes engaged in the translation of random and focused transcript libraries, and demonstrate its usefulness for rapidly assaying context-specific translation inhibition by ribosome-targeting compounds.

\section{Results}

\section{Inverse toeprinting maps stalled ribosomes with codon resolution while preserving the upstream coding region}

Ribosome profiling generates short footprints and thus loses sequence information for most of the coding region, whereas classical toeprinting (Hartz et al, 1989; Orelle et al, 2013) determines the exact position of a ribosome on the mRNA, but is not suitable for largescale analyses (Fig 1A). By contrast, inverse toeprinting relies on RNase R, a 3' to 5' RNA exonuclease that efficiently degrades mRNA with a 3' poly-(A) tail (Vincent \& Deutscher, 2006). Our assumption was that RNase $\mathrm{R}$ would digest the mRNA up to a precise, discrete position downstream of the P-site codon of the foremost stalled ribosome-nascent chain complex. Inverse toeprints obtained in this manner could be analyzed by deep sequencing or evolved through multiple rounds of selection (Figs 1B and S1A).

As a proof-of-principle for inverse toeprinting, we generated a 5'-biotinylated (Fig S1B) and 3'-polyadenylated (Fig S1C) mRNA template encoding the erythromycin resistant methyltransferase $\mathrm{B}$ leader peptide (ErmBL), followed by a short coding region ending with a UGA stop codon. This template was used to express ErmBL in a PURE E. coli translation system (Shimizu et al, 2001) in the absence of release factor 2 (RF-2), which promotes peptide release at UGA or UAA stop codons (Scolnick et al, 1968), and in the absence or presence of the macrolide antibiotic erythromycin (Ery). ErmBL undergoes translational arrest in an antibiotic-dependent manner (Arenz et al, 2014; Vázquez-Laslop et al, 2010), a property that is used in vivo to induce the expression of a methyltransferase gene on the same mRNA that confers resistance to macrolide antibiotics (Horinouchi \& Weisblum, 1980). We chose ErmBL because it has been extensively characterized biochemically (Min et al, 2008; Gupta et al, 2016) and its structure has been determined within the context of a drug-stalled ribosome (Arenz et al, 2014; Arenz et al, 2016). In the presence of Ery, ribosomes undergo strong translational arrest when codon 10 of ermBL is in the ribosomal P-site, whereas in the absence of the drug ribosomes reach the UGA stop codon and stall because of the absence of RF-2. RNase R treatment yielded either short or long $3^{\prime}$-truncated mRNA fragments for ribosomes arrested at these two positions (Figs $1 \mathrm{C}$ and S1C). Ribosome-protected mRNAs were ligated to a 3' linker enabling reverse transcriptase priming. Ribosomes stalled at the UGA stop codon protected an ECoRV site on the mRNA, which could be cleaved after reverse transcription and second strand synthesis. Thus, only short cDNA fragments derived from messengers encoding sequences that caused drug-dependent translational arrest were amplified by PCR after ECoRV treatment (Fig 1C). Similar experiments performed with other arrest peptides (ErmAL1, ErmCL, ErmDL, SecM, and TnaC) showed that inverse toeprinting can be used as a general tool for selecting arrest sequences (Fig 1D). Moreover, we showed that it is possible to perform consecutive rounds of selection by alternating restriction enzymes on the $3^{\prime}$ oligonucleotide linkers (Fig S1D). This could be used in the future as the basis for a SELEX-like (Ellington \& Szostak, 1990; Tuerk \& Gold, 1990) scheme to identify rare arrest sequences contained within a complex transcript pool.

To test the scalability of our method for high-throughput assays, we performed inverse toeprinting on an in vitro translation reaction using a template library ( $\mathrm{NNS}_{15}$ library) encoding 20-residue peptides with a variable region of 15 NNS codons, where $\mathrm{N}$ and $\mathrm{S}$ denote equal proportions of the four possible nucleotides or of $G$ or $C$, respectively (Fig S2A). We size-selected inverse toeprints to minimize contamination from DNA fragments resulting from initiation complexes (Fig S3). The accumulation of initiation complexes was probably due to initiation being the rate-limiting step of translation and is also observed in the form of increased ribosomal density corresponding to initiation complexes in ribosome profiling experiments (Woolstenhulme et al, 2015). Removing these fragments ensured that more useful reads could be sequenced and could not introduce significant bias into our analysis. Paired-end Illumina sequencing revealed a tri-nucleotide periodicity for fragments where RNase R cleavage had occurred 24-47 nucleotides downstream of the start codon (Fig 1E). Longer fragments did not follow this size periodicity and were excluded from our analysis.

UAG stop codons were enriched 1.4-fold after inverse toeprinting, indicating that ribosomes pause on these codons, despite the presence of release factor 1 (RF-1) (Scolnick et al, 1968) in the translation reaction. This pausing was used to precisely characterize the protective effect of stalled ribosomes on the mRNA. Given that ribosomes pause when they encounter a UAG stop in the A-site, our analysis revealed a distinct three-nucleotide peak positioned +17 nucleotides downstream from the ribosomal P-site (Fig 1F). This RNase R cleavage pattern was also confirmed for all of the arrest peptides we tested, allowing us to locate a second stalling site for the drug-dependent arrest peptide ErmAL1 that had been overlooked in 
A

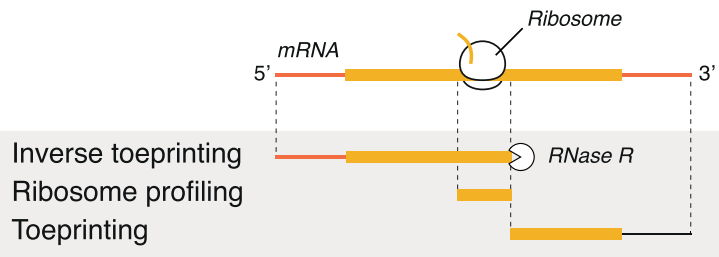

C

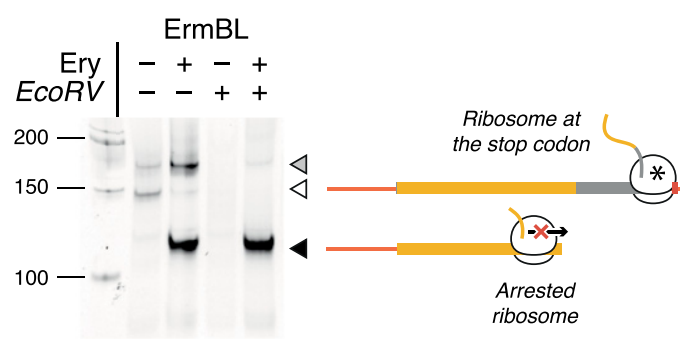

D
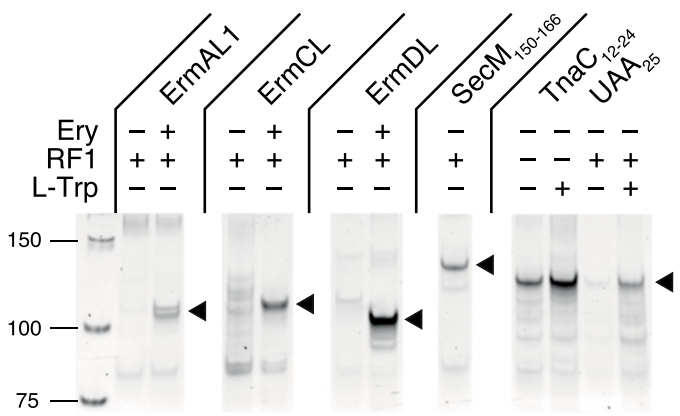

E

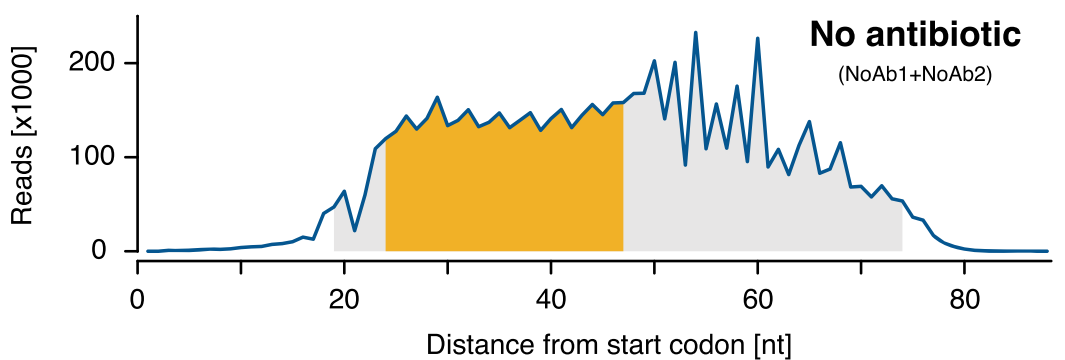

B

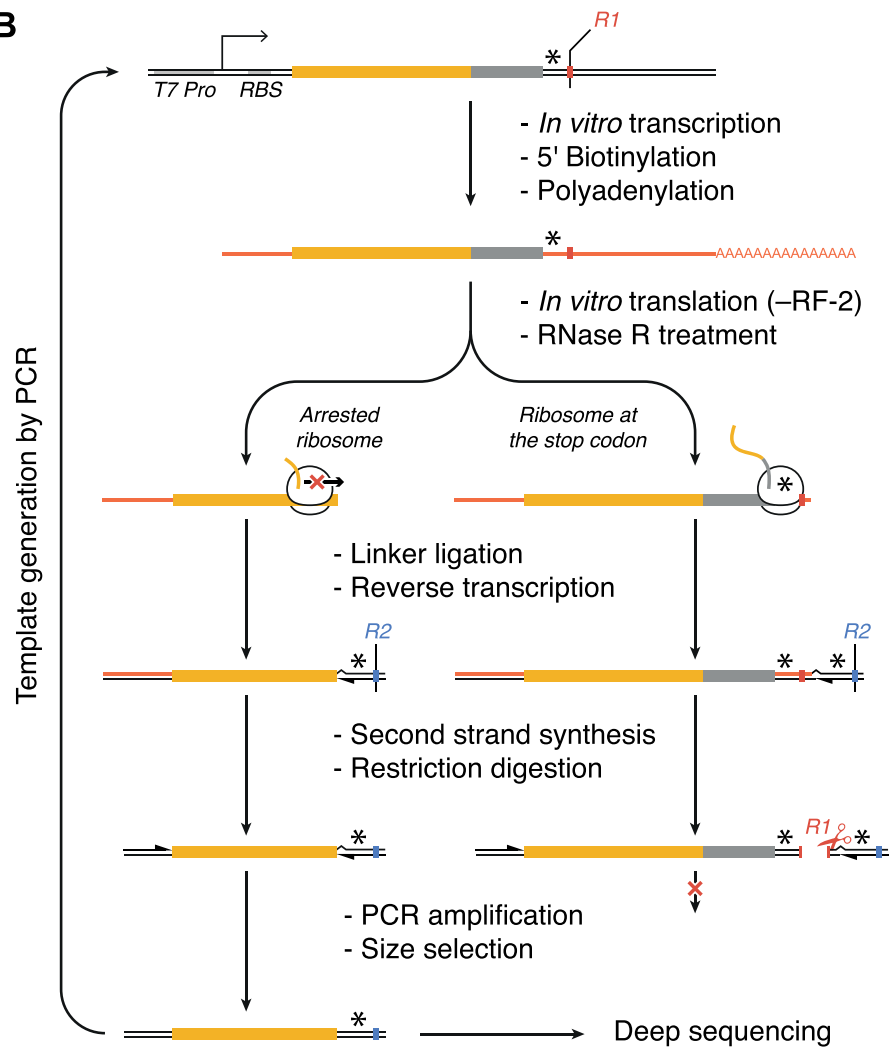

Figure 1. Inverse toeprinting locates ribosomes on the mRNA with codon resolution.

(A) Comparison between inverse toeprinting, ribosome profiling, and classical toeprinting. (B) Schematic overview of the inverse toeprinting workflow. Restriction enzymes used in odd (ECORV) and even (Apol) cycles are shown in red and blue, respectively. Stop codons are indicated as asterisks. (C) Removal of inverse toeprints featuring ribosomes that have reached the stop codon on the ermBL template (white triangle) using the EcoRV restriction enzyme. The black triangle corresponds to arrested ribosomes and the gray triangle to full-length mRNA. (D) Inverse toeprints for various Erm peptides in the absence or presence of Ery, SecM $150-166$, and $\mathrm{TnaC}_{12-24} \mathrm{UAA}_{25}$. The wild-type UGA 25 stop codon for TnaC was replaced with a UAA 25 stop codon, allowing its release by RF-1. (E) Size distribution of inverse toeprints from two biological replicates (NoAb1 and NoAb2) with a minimum Q-score of 30 obtained from an NNS 15 library translated in the absence of any added antibiotic. The fragment size range shaded in gray corresponds to the band that was cut from a $12 \%$ TBE-acrylamide gel, whereas the range in yellow indicates fragments that were used in the subsequent analysis. (F) Analysis of inverse toeprints containing stop codons that were obtained in the absence of antibiotic reveals that RNase $R$ cleaves +17 nucleotides downstream from the P-site.

previous studies (Ramu et al, 2011; Vázquez-Laslop et al, 2010) (Fig S4A-F). Thus, inverse toeprinting can be used to determine the position of stalled ribosomes on the mRNA at codon resolution.

\section{Motif enrichment correlates with pause strength and in vivo data}

To assess whether sequences enriched following inverse toeprinting correlated with their ability to induce translational arrest or pausing, we first estimated the reproducibility of the frequency of occurrence of 3-aa motifs of the type $X_{1} X_{2}\left(X_{3}\right)$ (where $X_{2}$ is in the $\mathrm{P}$-site and $X_{3}$ in the A-site) between independent biological replicates. From $\sim 3.4$ million inverse toeprints obtained after translation in the absence of antibiotics, we could precisely (Fig S5) and reproducibly measure the frequency of 5,278 of 8,000 possible 3-aa motifs ( $R^{2}=0.95 ;<15 \%$ error between biological replicates) (Fig 2A). To limit the impact of the noise resulting from poor counting statistics, we chose to limit our subsequent analysis to this subset of well-measured 3-aa motifs. Because the vast majority of 3-aa 
A

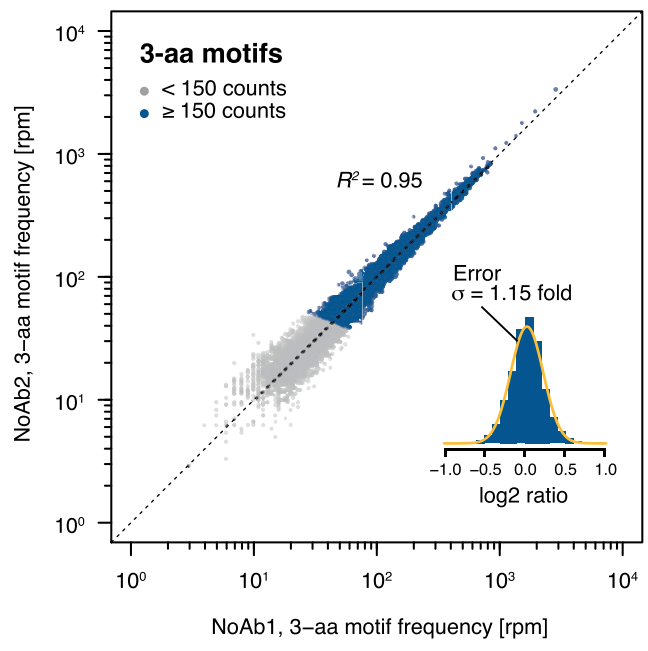

D

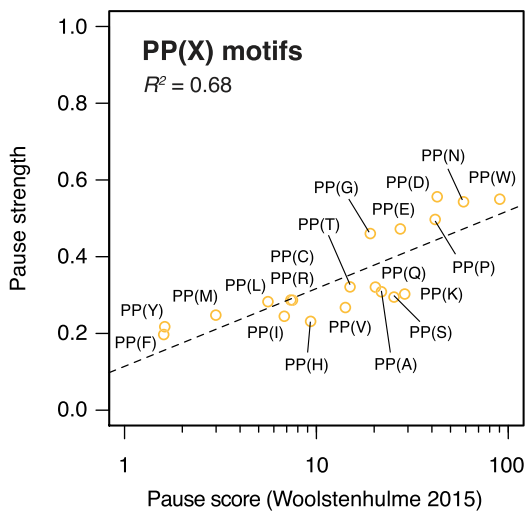

B

Pause strength $=\frac{n_{\mathrm{P}}}{n_{\mathrm{P}}+n_{\mathrm{B}}}=0.45$
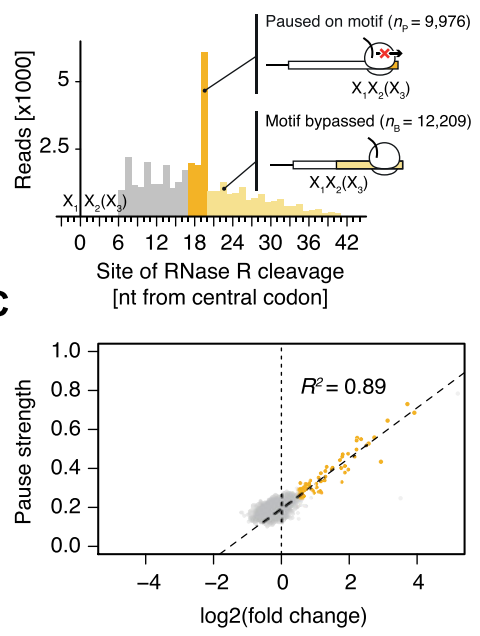

E

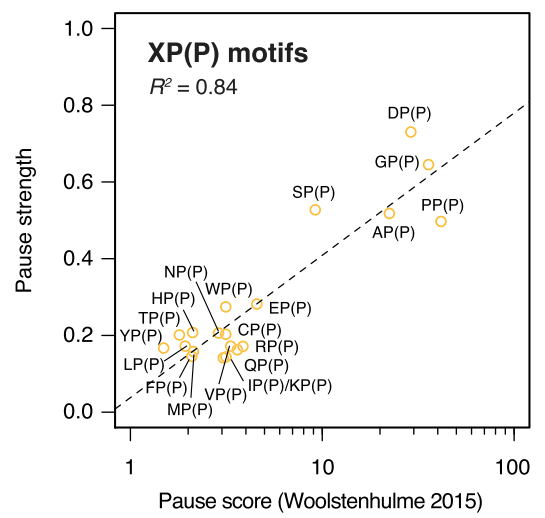

Figure 2. Motif pause strength correlates with enrichment on inverse toeprinting.

(A) 3-aa motif frequencies in reads per million (rpm) from two independent inverse toeprinting experiments performed after translation in the absence of antibiotic (NoAb1 and NoAb2). The inset represents a histogram of log2 ratios between replicates for 3-aa motifs having low statistical counting error (i.e., with >150 counts [blue], Fig S5), with an overlaid normal error curve (mean $=0.02, S D=0.2$ log2 units, equivalent to $\sigma=1.15$ fold). (B) Formula used to calculate pause strength for an $X_{1} X_{2}\left(X_{3}\right)$ motif, with the amino acid in the ribosomal A-site in brackets. (C) Plot of pause strength against log2 (fold change) of all possible 3-aa motif frequencies relative to the $\mathrm{NNS}_{15}$ library. Yellow points correspond to intrinsic 3-aa pause motifs with a pause strength $\geq 0.25$. All other motifs are shown as gray dots. (D, E) Plot of pause strengths calculated in this study against pause scores calculated from ribosome profiling data obtained from E. coli cells lacking EF-P, for (D) PP(X) and (E) XP(P) motifs (Woolstenhulme et al, 2015). The scores obtained by both methods are strongly correlated, as indicated by $R^{2}$ values of 0.68 and 0.84 for $\mathrm{PP}(\mathrm{X})$ and XP (P) motifs, respectively. motifs were well represented in the input library (i.e., only 11 motifs had $<150$ reads in the sequenced $N_{N S}{ }_{15}$ library), poorly measured 3-aa motifs were depleted during the selection process because they did not induce sufficiently strong pauses in translation. Their exclusion therefore does not limit or bias our analysis.

Next, we devised a means to quantify the strength of translational pausing for each 3-aa motif, which we call the pause strength (Fig 2B). This represents the number of times a ribosome is stalled on a given motif divided by the number of times ribosomes have encountered that motif. Consequently, a value of one indicates a very strong pause (i.e., ribosomes never bypass that motif), whereas a value of 0.2 indicates a weak pause (i.e., $80 \%$ of the ribosomes that encountered this motif bypassed it and stalled at another motif downstream on the mRNA). We found a strong linear correlation between the pause strength and the log2 (fold change) in frequency for all motifs exhibiting a pause strength greater than 0.25 (Fig 2C). By contrast, the change in 3-aa motif frequency on selection did not correlate with E. coli codon usage frequencies, indicating that translational pauses induced by consecutive rare or low usage codons are not detected by inverse toeprinting (Fig S6). Pause strengths were in the range of $0.1-0.8$, with values less than 0.25 found for most motifs. In the absence of antibiotic, PP $(X)$ and XP (P) motifs displayed pause strengths that were strongly correlated with the "pause scores" calculated for the same motifs from ribosome profiling experiments performed in EF-P-deficient E. coli (Woolstenhulme et al, 2015) (Fig 2D and E). Although PP(X) motifs on the whole appear to be more efficient at pausing translation (PP $(D)>P P(W)>P P(N)>P P(P)>P P(E)>P P(G)$ ), the strongest $X P(P)$ motifs $(D P(P)>G P(P)>S P(P)>A P(P)>P P(P))$ exhibit the greatest pause strengths. We also identified an additional intrinsic arrest motif $(X P(C)$ ), where $X$ matches the amino acids in $X P(P)$ motifs that cause the strongest pauses (i.e., $A, D, G, S$ ).

We then sought to identify short 3-aa motifs that arrest ribosomes in response to the macrolide antibiotic Ery. Previous studies have shown that ribosomes translating in the presence of Ery stall when they encounter $+X(+)$ motifs ("+" being the positively charged amino acids arginine or lysine) (Davis et al, 2014; Kannan et al, 2014; Sothiselvam et al, 2014). We performed inverse toeprinting on an in vitro translation reaction using the $\mathrm{NNS}_{15}$ library in the presence of Ery. Paired-end Illumina sequencing of the corresponding inverse toeprints revealed a strong tri-nucleotide periodicity of fragment sizes compared with the samples without antibiotic (Fig S7). Comparison of independent biological replicates, obtained in the presence of Ery, allowed us to identify a subset of wellmeasured 3-aa motifs derived from inverse toeprints (Fig S8). From this subset, we measured the enrichment of 3-aa motifs in 
inverse toeprints obtained after translation in the presence of Ery relative to those obtained in the absence of antibiotic, and calculated a mean error of 1.2-fold change in motif frequency upon addition of Ery (Fig 3A). Several classes of 3-aa motifs that were significantly enriched in the Ery sample were characterized by relatively high pause strengths (Figs $3 \mathrm{~A}$ and $\mathrm{C}, \mathrm{S} 9, \mathrm{S10}$ ), not seen in the absence of the drug (Fig $3 \mathrm{~B}$ ). These include the previously reported $+X(+)$ motif, the general $X P(X)$ motif and its subsets $+X(W)$ and $X P(W)$, with the latter's ability to induce pausing in vitro correlating well with the results of our in vivo assay (Fig 3D and E). Among these motifs, most $\mathrm{XP}(\mathrm{X})$ motifs induced significant drugdependent pauses in the presence of EF-P, but not in its absence (Fig S11). The molecular basis for this phenomenon is unclear at present and will need to be further investigated.

Thus, inverse toeprinting provided us with a detailed view of the translational pausing landscape of drug-free and drug-bound E. coli ribosomes that matches and complements earlier in vivo profiling data (Woolstenhulme et al, 2015). Motif enrichment upon inverse toeprinting and pause strength are strongly correlated, indicating the robustness of the selection procedure. This will be useful in identifying longer and hence less frequently occurring arrest motifs for which pause strengths cannot be calculated.

\section{Inverse toeprinting identifies arrest peptide variants that discriminate between closely related ligands}

To test the ability of inverse toeprinting to detect targets in a high complexity library, we used the method to identify ErmBL variants (Fig S2B) that were differentially enriched in the presence of Ery (Fig $4 \mathrm{~A}$ ) or of the weaker antibiotic oleandomycin (Ole) (Fig 4B). After paired-end Illumina sequencing, 1.3 million library reads were aligned to the wild-type ermBL sequence, corresponding to 724,573 unique protein variants. The observed distribution of mutations ( $100 \%$ of single mutants and $~ 55 \%$ of double mutants) within the library (Table S1) closely approximated the expected distribution based on the mutation rate of $7 \%$ used at each nucleotide position of ermBL. Inverse toeprints obtained after translation in the presence of Ery or Ole featured $>230,000$ unique protein variants in each case, $~ 80 \%$ of which were sequenced more than once.

Comparison of the sequence variants that were obtained in the presence of Ery or Ole revealed amino acids that were over- or underrepresented at each position of ErmBL in response to the antibiotics (Fig S12). Leucine was enriched at position seven of ErmBL ( -3 relative to the amino acid in the ribosomal $P$-site) in the presence of Ery, but not Ole. Several mutants encoding leucine at this position underwent translational arrest exclusively in the presence of Ery (Table S2). We further characterized the L7 single mutant and L7K8 double mutant of ErmBL, both of which were enriched $\sim 1.9$-fold in the Ery sample compared with the input library, whereas they were not significantly enriched in the Ole sample (0.7-fold and 0.5-fold, respectively). The L7 and L7K8 mutants originated from 198 and 55 unique variants at the nucleotide level, respectively, indicating multiple independent events. Using an in vitro toeprinting assay (Fig 4C) and an in vivo reporter to measure translational arrest (Bailey et al, 2008) (Fig 4D), we confirmed the antibiotic specificity for the L7 and L7K8 mutants. The weak Ery-dependent toeprints obtained in vitro contrasted with
A

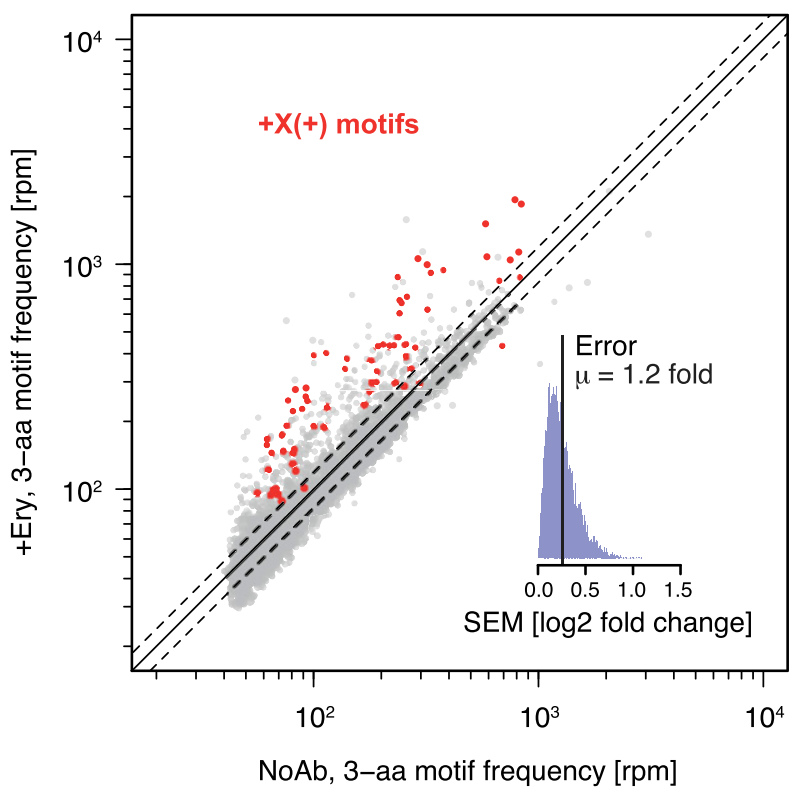

B

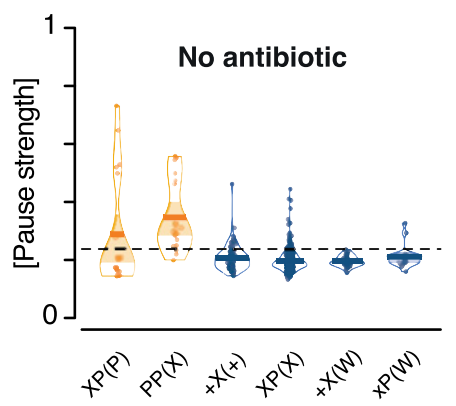

C
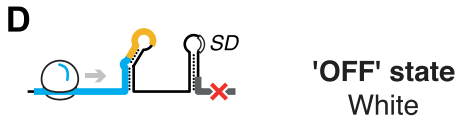

E

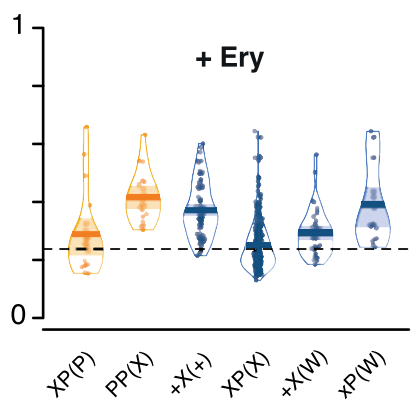

[Pause strength]

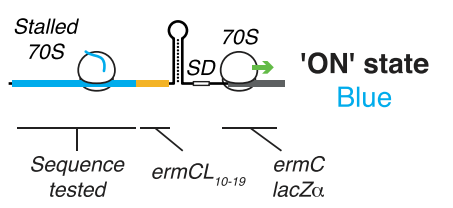

GP(W) TP(W) PP(W) KP(W) $\begin{array}{llll}0.23 & 0.41 & 0.59 & 0.67\end{array}$

+ Ery

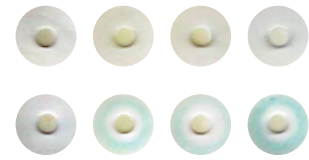

Figure 3. Nascent peptide-dependent translational arrest in response to Ery. (A) Frequency of occurrence of 3-aa motifs with low statistical counting error in inverse toeprints obtained in the absence or presence of Ery, with $+X(+)$ motifs indicated in red. The inset represents a histogram of the SEM of the log2 fold change in 3-aa motif frequency upon addition of Ery. The upper and lower dotted lines (gray) indicate 1.20 and 0.83 -fold changes, respectively, corresponding to the mean $(\mu)$ of the distribution of SEM (log2 fold change). (B, C) RDI (raw data, description and inference) plot showing pause strengths for individual motifs translated in the (B) absence or (C) presence of Ery. Polyproline motifs are shown in yellow and all other motifs are in blue. The horizontal dashed line corresponds to the 0.25 pause strength cutoff used to identify motifs that are enriched upon addition of Ery. (D) Overview of the lacZa-complementation assay used to test the in vivo activity of ErmBL variants (modified from Bailey et al [2008]). (E) Discdiffusion test plates used to assay the ability of nascent formyl-MAXP(W) to cause translational arrest in vivo. Discs marked with +Ery contain this antibiotic and blue rings result from the induction of a lacza reporter in response to ribosome stalling at an upstream test ORF (modified from Bailey et al [2008]). 
A

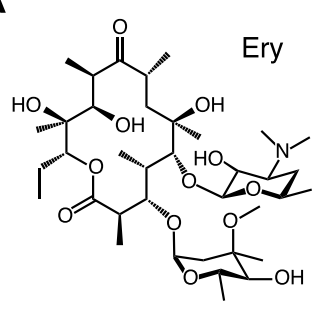

B

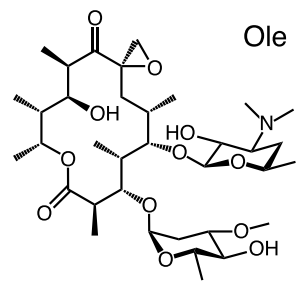

C

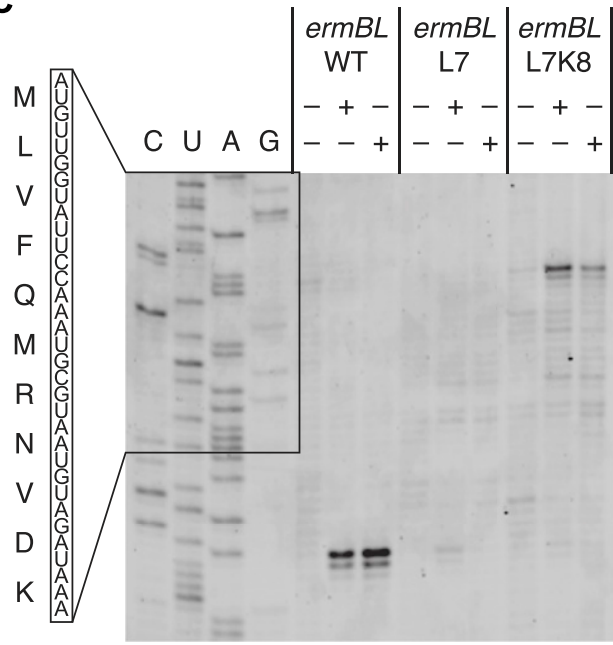

D Ery

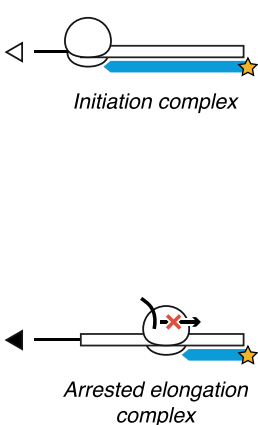

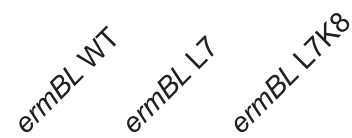

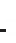

(n)
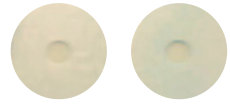

+Ery
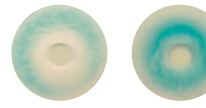

+ Ole

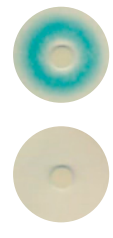

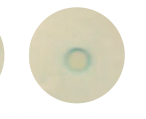

Figure 4. The ErmBL L7 and L7K8 mutants discriminate between closely related antibiotics.

(A, B) Chemical diagrams for Ery and Ole. (C) Classical toeprinting analysis of translational arrest by wild-type ErmBL (ermBL WT), an L7 single mutant (ermBL L7), and an L7K8 double mutant (ermBL L7K8), in the absence or presence of the antibiotics Ery and Ole. The white arrow indicates ribosomes on the start codon, and the black arrow indicates arrested elongation complexes with the GAU codon encoding Asp-10 in the ribosomal P-site. The sequence of wild-type ErmBL is shown. (D) Discdiffusion test plates used to assay the ability of nascent ErmBL WT, ErmBL L7, and ErmBL L7K8 to cause translational arrest in vivo in the absence or presence of Ery or Ole soaked into paper discs. It should be noted that the double mutant shows greater antibiotic selectivity in vivo compared with the single mutant, as indicated by the light blue ring observed in the +Ole condition for the ErmBL L7 mutant.

strong $\beta$-galactosidase activity in vivo, indicating that arrest sequences that appear weak by toeprinting can stall ribosomes effectively in vivo. The L7 and L7K8 mutants could not have been predicted based on the available structure of a stalled ErmBL-70S complex (Arenz et al, 2016) and would not have been identified using alanine-scanning mutagenesis of ErmBL. The weak toeprint signals would also likely have been overlooked, highlighting the value of inverse toeprinting for exploring the sequence space of known arrest peptides or for identifying specific variants out of a high complexity library.

\section{Discussion}

We developed inverse toeprinting, an in vitro selection method that locates stalled ribosomes on the mRNA with codon resolution while also preserving the coding region upstream of the point of arrest. This presents a major advantage over current methods, such as ribosome profiling, when a reference genome is not available for mapping protected mRNA footprints, but the encoded amino acid sequence needs to be known. The complexity of the input transcript library can be fine-tuned to match the biological question to be addressed, making it possible to limit the reaction volume and measure the effect of tens if not hundreds of different conditions in a parallel fashion. Importantly, inverse toeprinting can provide comparable results with in vivo methods such as ribosome profiling, making it a robust and convenient framework for developing more complex methods.

Here, we used inverse toeprinting to characterize the translational pausing landscape of free and drug-bound bacterial ribosomes. The large number of conditions that can be analyzed at a time with this technique makes it a valuable tool for the rapid characterization of antibiotics and compounds that inhibit the bacterial ribosome. For example, sequence-dependent inhibition profiles could be established for entire collections of macrolide derivatives obtained by a novel total synthesis approach (Seiple et al, 2016; Dinos, 2017). This would, in turn, provide fresh insights into the mechanism of macrolide action that could inform the development of new drugs by rational design. Another application of inverse toeprinting is the identification of arrest peptide variants with specificities for closely related small molecules, as shown by the ErmBL variants that respond differently to chemically similar antibiotics. A similar strategy could be applied to naturally occurring arrest peptides such as TnaC (Gong et al, 2001) or the fungal arginine attenuator peptide (Luo \& Sachs, 1996), which arrest translation in response to elevated levels of amino acids in the cell. Biological sensors that respond to unnatural amino acid derivatives or other compounds of interest in a dose-dependent manner could find uses in a number of synthetic biology or biotechnological applications.

Identifying small molecule-dependent arrest peptides encoded within a truly random transcript library poses some additional challenges. Indeed, these peptides are likely to occur very infrequently and may therefore be more difficult to isolate that the much larger number of functional variants that exist within a focused library. Consequently, it may be necessary to incorporate inverse toeprinting into a more complex and more sensitive SELEXlike procedure. We have shown that the enrichment of arrestinducing sequences is strongly correlated with their pause strength. This is important as it establishes the effectiveness of inverse toeprinting as a selection tool to identify rare arrest sequences hidden within a high complexity library. Although our method allows us to perform consecutive rounds of selection, it will 
be necessary to develop a counter-selection procedure to reduce the number of false positives after each round. In particular, we will need to address the incomplete recycling of ribosomes at stop codons that is observed currently.

The fact that inverse toeprinting is an in vitro method offers some advantages relative to in vivo approaches when it comes to identifying arrest peptides that sense small molecules. Indeed, problems may arise in vivo because of the inefficient uptake of small molecules into the cell, their degradation, modification, or their accelerated efflux out of the cell. An additional advantage of our in vitro method is that it enables us to dissect molecular processes in isolation by giving us direct control over the reaction conditions. Being able to remove certain molecular processes from their cellular context is a double-edged sword however, and care must be taken to validate results obtained by inverse toeprinting with in vivo assays. For the systems studied here, the correlation between in vitro and in vivo data is generally good, but the small discrepancies observed could be due to the $\mathrm{NNS}_{15}$ library's intrinsic focus on the early cycles of translation, where the nascent peptide is not yet fully threaded inside the ribosomal exit tunnel. These and other as yet unforeseen considerations will need to be taken into account as the method is developed further.

\section{Materials and Methods}

\section{Method overview}

The DNA template encoding a T7 RNA promoter, followed by a ribosome binding site, a potential arrest peptide, a fixed "spacer" region of four codons, two TGA stop codons, and an ECORV restriction site are generated by PCR and subsequently transcribed in vitro using T7 RNA polymerase with an excess of thio-phosphateGMP, which can only be incorporated at the $5^{\prime}$ end of the mRNA. In the next step biotin-maleimide is coupled to the $5^{\prime}$ thiol group on the mRNA. The 3' polyA-tail needed for efficient degradation by RNase $\mathrm{R}$ is added using Poly-A polymerase. $\sim 5 \mathrm{pmol}$ of this 5 '-biotinylated and 3'-polyadenylated mRNA is then used as a template for in vitro translation using a PURExpress kit (NEB) from which RF-2 is omitted to prevent the release of ribosomes that translate beyond the spacer sequence. Using an NNS (aNy a $\mathbf{N} y$ Strong-i.e., G or C) library ensures that no other UGA stop codons appear in the variable region. By contrast, ribosomes that reach the UAG stop codons found within the variable region can be released using RF-1.

Ribosomes engaged in translation of the mRNAs can either stall on the variable coding region if it encodes an arrest peptide or can translate until they reach the stop codon downstream of the spacer. RNase R is then used to degrade mRNAs from their $3^{\prime}$ end in the presence of $50 \mathrm{mM} \mathrm{Mg}^{2+}$, which inactivates and stabilizes ribosomes on the mRNA, thus ensuring that the upstream coding region is protected. Transcripts without ribosomes are degraded in this step. After this step, mRNAs are subjected to a phenolchloroform extraction to ensure the inactivation and removal of RNase $\mathrm{R}$ and of the ribosomes. The mRNAs are purified via their 5 '-biotin using streptavidin-coupled Dynabeads. In the next step, a DNA oligonucleotide linker is attached enzymatically to the $3^{\prime}$ end of the mRNA. This linker contains a fixed "spacer" region, followed by three TGA stop codons, one in each reading frame, followed by a restriction site. Two different linker oligonucleotides were used in this study, one encoding an Apol restriction site and one encoding an ECORV restriction site. Adding the linker generates a $3^{\prime}$ end of known sequence needed for reverse transcription of the mRNA. After second strand synthesis, the double stranded CDNA is treated with the restriction enzyme encoded in the DNA template (ECoRV for odd rounds of selection and Apol for even rounds). Ribosomes that reach the stop codon (and thus translated a sequence that does not induce stalling) protect the restriction site from RNase $R$ degradation, thus allowing restriction enzymes to cut these DNAs and prevent their amplification in the following PCR step. Double stranded cDNAs derived from mRNAs coding for peptides that arrested the ribosome do not contain the restriction site and are consequently amplified in the ensuing PCR. The ECORV and Apol sites have a stretch of at least four A/Ts and thus cannot occur within the $\mathrm{NNS}_{15}$ region. PCR products from this step serve as templates for either another round of inverse toeprinting through the addition of a $T 7$ promoter, or for NGS library generation and deep sequencing.

\section{Experimental procedures}

DNA and RNA products at various points in the inverse toeprinting protocol were analyzed on 9\% acrylamide (19:1) TBE (90 mM Tris, $90 \mathrm{mM}$ boric acid, and $2 \mathrm{mM}$ EDTA) gels and stained with SyBR Gold (Invitrogen). Inverse toeprints were excised from $12 \%$ acrylamide TBE gels using a clean scalpel. Gels to analyze RNA were run under denaturing conditions ( $8 \mathrm{M}$ urea in the gel). All reactions were performed using molecular biology grade $\mathrm{H}_{2} \mathrm{O}$ (Millipore). Oligonucleotides used in this study are listed in Tables S3-S6.

\section{DNA template generation}

All DNA templates for inverse toeprinting were generated by PCR with Phusion DNA polymerase, using an oligonucleotide encoding the variable region in combination with oligonucleotides T7_RBS_ATG_f and Stop_ECORV_r as templates. Amplification was performed using oligonucleotides T7_f and ECORV_r in 10-fold excess. PCR conditions included an annealing temperature of $64^{\circ} \mathrm{C}$ and 20 cycles of amplification. DNA templates were generated using a total of 5 pmol ermBL_deep_mutated oligonucleotide or $10 \mathrm{pmol}$ NNS15 oligonucleotide, respectively. PCR products were purified using a PCR purification kit (Qiagen) according to the manufacturer's instructions and were used as templates for in vitro transcription.

\section{In vitro transcription}

The DNA template encodes a T7 promoter followed by an optimized Shine-Dalgarno sequence, according to the instructions of the NEB PURExpress system handbook. In vitro transcription was performed using T7 RNA polymerase (Promega) in a buffer containing $80 \mathrm{mM}$ Tris- $\mathrm{HCl}, 24 \mathrm{mM} \mathrm{MgCl}$, 2 mM spermidine, and $40 \mathrm{mM} \mathrm{DTT}$, pH 7.6, in the presence of $7.5 \mathrm{mM}$ ATP (Sigma Aldrich), CTP and UTP, $0.75 \mathrm{mM}$ GTP (CTP, UTP, and GTP from Jena Bioscience), and $6.75 \mathrm{mM}$ Thio-Phosphate-GMP (Genaxxon). In the first round of inverse toeprinting, $10 \mathrm{ng} / \mu \mathrm{l}$ of DNA template were used; for further rounds, 
the amount was reduced to $1 \mathrm{ng} / \mu \mathrm{l}$. In vitro transcription was performed at $37^{\circ} \mathrm{C}$ for $2-3 \mathrm{~h}$, mRNA was purified by phenolchloroform extraction, washed three times with chloroform and precipitated using 0.1 volumes of $\mathrm{NH}_{4}$-acetate $(10 \mathrm{M})$ and 1 volume of isopropanol. To remove unincorporated nucleotides, the recovered mRNA was subsequently washed through Amicon membrane centrifugal concentrators with a molecular weight cutoff (MWCO) of $30 \mathrm{kD}$ (Millipore) until the flow-through was free of unincorporated nucleotides (as determined by NanoDrop measurements). The final concentration of mRNA was determined using the NanoDrop.

\section{Biotinylation}

Biotinylation was performed using a 1,000-fold excess of biotinmaleimide (Vectorlabs) over mRNA 5' ends. According to the manufacturer's instructions, the biotin-maleimide was dissolved in dimethylformamide. $600 \mathrm{pmol}$ mRNA were mixed with $600 \mathrm{nmol}$ biotin-maleimide in 100 mM in Bis-Tris-acetate buffer pH 6.7 and incubated at room temperature for $3 \mathrm{~h}$. Unincorporated biotin was removed by washing the mRNA three times with $\mathrm{H}_{2} \mathrm{O}$ (molecular biology grade, Millipore) in an Amicon membrane centrifugal concentrator with a MWCO of $30 \mathrm{kD}$ (Millipore). mRNA was recovered and biotinylation efficiency was analyzed using a dot blot.

\section{Dot blot}

$\mathrm{H}^{+}$bond membrane (GE Healthcare) was treated with 6× SSC buffer ( $900 \mathrm{mM} \mathrm{NaCl}, 90 \mathrm{mM} \mathrm{Na}_{3}$-citrate, pH 7.0) for 10 min and dried briefly between two pieces of Whatman paper. Samples and the standard were diluted in $6 \times$ SSC buffer to $0.5,1.0,2.5$, and $5.0 \mu \mathrm{M}$, and $1 \mu \mathrm{l}$ of each dilution was pipetted onto the prepared membrane. The membrane was then baked for $2 \mathrm{~h}$ at $80^{\circ} \mathrm{C}$ to attach the mRNA to the membrane. The membrane was subsequently blocked in $2.5 \%$ dry milk solution in TBS-T $(50 \mathrm{mM}$ Tris- $\mathrm{HCl}, 150 \mathrm{mM} \mathrm{NaCl}$, and $0.05 \%$ [vol/vol] Tween-20, pH 7.5) for $1 \mathrm{~h}$ at room temperature. The milk solution was removed and the membrane was incubated with streptavidin-alkaline phosphatase antibody (Promega) in a 1:1,000 dilution in TBS-T for $1 \mathrm{~h}$ at room temperature. Unbound antibody was removed by washing three times with TBS-T buffer. Detection was performed using the NBT/BCIP detection kit (Promega) in alkaline phosphatase buffer according to the manufacturer's instructions. The detection reaction was stopped by two washes with TBS-T buffer and an image of the membrane was acquired immediately on a Bio-Rad Imager. The biotinylation efficiency was estimated from the intensity of the sample dots compared with the intensity of the standard dots.

\section{Poly-adenylation of the MRNA $3^{\prime}$ end}

Poly-adenylation of the biotinylated mRNA was performed using Poly-A polymerase (NEB) using the supplemented buffer. The ratio of mRNA $3^{\prime}$ ends to ATP molecules was chosen to be 1:100. The reaction was incubated at $37^{\circ} \mathrm{C}$ for $2-3 \mathrm{~h}$ and poly-adenylation efficiency was assessed by denaturing PAGE (9\%). Polyadenylated mRNA was subjected to a phenol-chloroform extraction, washed three times with chloroform, and precipitated with $\mathrm{NH}_{4}$-acetateisopropanol with $0.5 \mu \mathrm{l}$ GlycoBlue (Thermo Fisher Scientific). Unincorporated ATP was removed by successive washes in Amicon membrane centrifugal concentrators with a MWCO of $30 \mathrm{kD}$ (Millipore).

\section{RNase $R$ activity}

Purified RNase R (Suzuki et al, 2006) was provided by Dr. Arun Malhotra (University of Miami) and was used at $1 \mathrm{mg} / \mathrm{ml}$ stock solution. $5 \mathrm{pmol}$ of mRNA were used to test the degradation efficiency of $2 \mu \mathrm{l}$ RNase R on every batch of mRNA in a buffer containing $50 \mathrm{mM}$ Hepes-KOH, $100 \mathrm{mM} \mathrm{K}$-glutamate, $50 \mathrm{mM} \mathrm{Mg}$-acetate, and $1 \mathrm{mM}$ DTT, pH 7.5. Time points were taken directly into RNA loading dye (95\% formamide, $250 \mu \mathrm{M}$ EDTA, 0.25\% [wt/vol] bromophenol blue, and $0.25 \%$ [wt/vol] xylene cyanol) before addition of the enzyme and after 5,10 , and $30 \mathrm{~min}$ of incubation at $37^{\circ} \mathrm{C}$. The samples were analyzed by denaturing PAGE (9\%), stained with SyBR Gold to monitor mRNA degradation.

\section{Inverse toeprinting}

PURExpress $\triangle$ RF-123 kit (NEB) was used to perform in vitro translation. $~ 5$ pmol of 5'-biotinylated and 3'-polyadenylated mRNA were used as a template. Antibiotics (Ery, Ole) were supplemented at a final concentration of $50 \mu \mathrm{M}$ in $10 \mu \mathrm{l}$ reactions. RF-1 and RF-3 were added to the translation reaction according to the manufacturer's instructions. Translation was performed at $37^{\circ} \mathrm{C}$ for $30 \mathrm{~min}$ before the samples were placed on ice and $10 \mu \mathrm{l}$ ice-cold $\mathrm{Mg}^{2+}$ buffer (50 mM Hepes- $\mathrm{KOH}, 100 \mathrm{mM} \mathrm{K-glutamate,} 87 \mathrm{mM} \mathrm{Mg-}$ acetate, and $1 \mathrm{mM}$ DTT, $\mathrm{pH}$ 7.5) was added to the reactions, thus increasing the $\mathrm{Mg}^{2+}$ concentration to $50 \mathrm{mM} .2 \mu$ l of RNase R $(1 \mathrm{mg} / \mathrm{ml})$ was added, followed by an additional incubation for $30 \mathrm{~min}$ at $37^{\circ} \mathrm{C}$ for RNase R-mediated mRNA degradation. Ribosomeprotected mRNA was purified by phenol-chloroform extraction, washed three times with chloroform, and precipitated using $\mathrm{NH}_{4}-$ acetate-isopropanol. RNA was recovered by centrifugation at full speed for $30 \mathrm{~min}$ at $4^{\circ} \mathrm{C}$ and resuspended in $50 \mu \mathrm{l} 1 \times$ BWT buffer (5 mM Tris- $\mathrm{HCl}, 0.5 \mathrm{mM}$ EDTA, $1 \mathrm{M} \mathrm{NaCl}$, and 0.05\% [vol/vol] Tween20, $\mathrm{pH} 7.5)$.

\section{mRNA purification with dynabeads}

$5 \mu \mathrm{l}$ M-280 streptavidin Dynabeads (Life Technologies) were prepared for each sample by washing three times with 1× BWT buffer in DNA loBind tubes (Eppendorf) and resuspended in $50 \mu \mathrm{l}$ of the same buffer. Dynabeads and purified RNA from the previous step were combined in these tubes and incubated on a tube rotator for $15 \mathrm{~min}$ at room temperature to allow binding of the biotinylated mRNA to the streptavidin beads. After incubation, the beads were collected using a magnet and the supernatant was discarded. The beads were washed two times with 1× BWT buffer to remove unincorporated RNA, followed by two washes with $\mathrm{H}_{2} \mathrm{O}$ to remove the $1 \times$ BWT buffer. Beads were resuspended in $4.5 \mu \mathrm{l} \mathrm{H}_{2} \mathrm{O}$.

\section{Linker ligation}

The beads from the previous step were combined with $10 \mathrm{pmol}(1 \mu \mathrm{l})$ of the desired linker (3'_linker_Apol or 3'_linker_ECoRV depending of the round of selection) plus $3 \mu \mathrm{L}$ PEG 8,000, $1 \mu \mathrm{l}$ PNK buffer, and $0.5 \mu$ T T4 RNA ligase 2, truncated (all NEB). Incubation was performed on a tube rotator for $2 \mathrm{~h}$ at room temperature. After incubation, the beads were washed three times with $\mathrm{H}_{2} \mathrm{O}$ to remove unincorporated linker oligonucleotide and were resuspended in $12 \mu \mathrm{l} \mathrm{H}_{2} \mathrm{O}$. 


\section{Reverse transcription}

$12 \mu \mathrm{l}$ beads were combined with $1 \mu \mathrm{l}$ Linker_r oligonucleotide $(2 \mu \mathrm{M})$ and $1 \mu \mathrm{L}$ 2'-deoxynucleotide triphosphates (dNTPs) (NEB, $10 \mathrm{mM}$ per dNTP), and incubated at $65^{\circ} \mathrm{C}$ for 5 min to allow annealing of the Linker_r oligonucleotide to the linker. After annealing, $4 \mu \mathrm{l}$ of first strand buffer, $1 \mu \mathrm{l}$ of $100 \mathrm{mM} \mathrm{DTT}$, and $1 \mu \mathrm{l}$ of superscript III (all Invitrogen) were added and the reaction incubated at $55^{\circ} \mathrm{C}$ for $30 \mathrm{~min}$ to allow reverse transcription of the Dynabead-bound mRNA.

\section{PCR on CDNA, restriction digestion}

Reverse transcribed CDNA was used without further purification as a template for PCR. To generate double stranded DNA for restriction digestion, a fill-up reaction was performed using CDNA_f oligonucleotide and the reverse transcribed cDNA (10 s denaturation, $5 \mathrm{~s}$ annealing at $42^{\circ} \mathrm{C}$, and $30 \mathrm{~s}$ elongation at $72^{\circ} \mathrm{C}$ ). The resulting dsDNA was combined with $1 \mu \mathrm{l}$ of the respective restriction enzyme and the sample was incubated at $37^{\circ} \mathrm{C}$ for $1 \mathrm{~h}$. To amplify undigested DNA, Linker_roligonucleotide was added and a PCR performed with 8-14 cycles (denaturation at $98^{\circ} \mathrm{C}$ for $10 \mathrm{~s}$, annealing at $42^{\circ} \mathrm{C}$ for $5 \mathrm{~s}$, and elongation at $72^{\circ} \mathrm{C}$ for $10 \mathrm{~s}$ ). The number of PCR cycles giving the best results was used for further purification of the CDNA.

\section{Purification of DNA fragments of interest after PCR}

Wild-type and ermBL samples were purified using a homemade electro-elution device. PCR products were analyzed by TBE-PAGE (12\%) and bands of interest were excised from the gel using a clean scalpel. Gel pieces were crushed through a $5 \mathrm{ml}$ syringe into $50 \mathrm{ml}$ Falcon tubes whose base ( $1-2 \mathrm{ml}$ ) had been cut off and covered with Parafilm. The crushed gel pieces were then embedded into a new 9\% acrylamide TBE gel inside the cut Falcon tube $(\sim 8 \mathrm{ml}$ of gel solution). After polymerization, DNA was eluted from the gel by filling the Falcon tube with TBE buffer (upper buffer reservoir) and hanging the Falcon tube into a beaker filled with TBE buffer (lower buffer reservoir, ice-cooled). DNA was eluted into the lower buffer reservoir by placing clean electrodes into the two buffer reservoirs and by applying a current of $10 \mathrm{~W}$ per gel (two gels max) for $30 \mathrm{~min}$. The buffer from the lower reservoir was recovered and the eluted DNA was concentrated using Amicon membrane centrifugal concentrators with a MWCO of $30 \mathrm{kD}$ (Millipore). DNA was precipitated by addition of $\mathrm{NH}_{4}$-acetate isopropanol and $0.5 \mu \mathrm{l}$ GlycoBlue (Thermo Fisher Scientific) and incubation at $-20^{\circ} \mathrm{C}$ for $1 \mathrm{~h}$.

The $\mathrm{NNS}_{15}$ library samples were purified as described, with modifications (Ingolia et al, 2012). After cutting out the bands of interest, the gel pieces were crushed through a $5 \mathrm{ml}$ syringe into $15 \mathrm{ml}$ Falcon tubes and $7.5 \mathrm{ml}$ of gel elution buffer (10 $\mathrm{mM}$ Tris- $\mathrm{HCl}$, $\mathrm{pH}$ 8.0, $500 \mathrm{mM}$ Na-acetate, and $0.5 \mathrm{mM} \mathrm{Na}$-EDTA) were added. The tubes were incubated on a tube rotator at room temperature overnight. Gel debris was separated from the buffer by filtering through $0.22 \mu \mathrm{m}$ centrifugal filters (Millipore). Each sample was then concentrated to $\sim 250 \mu \mathrm{l}$ using a SpeedVac. The eluted DNA was precipitated using 0.1 volume $\mathrm{NH}_{4}$-acetate and 2.5 volumes ethanol with $0.75 \mu \mathrm{l}$ GlycoBlue (Thermo Fisher Scientific) and incubation at $-20^{\circ} \mathrm{C}$ for $1 \mathrm{~h}$.

After precipitation, DNA was recovered by centrifugation in a tabletop centrifuge at full speed for $30 \mathrm{~min}$ at $4^{\circ} \mathrm{C}$. The supernatant was carefully removed by pipetting and the DNA pellet briefly dried in the SpeedVac for 10-15 min. The cDNA was then resuspended in $15 \mu \mathrm{L} \mathrm{H} \mathrm{H}_{2} \mathrm{O}$ (molecular biology grade) and used as a PCR template for the addition of the $\mathrm{T7}$ promoter sequence or the NGS adapters.

\section{Addition of the $T 7$ promoter for another round of inverse toeprinting}

The purified cDNA from the previous step was used as a template for PCR in combination with T7_RBS_ATG_f $(1 \mu \mathrm{M})$, encoding the T7 promoter needed for in vitro transcription, T7_f and Linker_r oligonucleotides (10 $\mu \mathrm{M}$ each). 8-14 cycles of PCR ( $64^{\circ} \mathrm{C}$ annealing temperature) were used and amplified DNA was purified using a Qiagen PCR purification kit. The concentration of purified DNA was determined using a NanoDrop.

\section{Addition of NGS adaptor to purified CDNA}

Long NGS adaptor oligonucleotides contain the Illumina TruSeq adapter sequences followed by 18 nucleotides complementary to the $5^{\prime}$ or $3^{\prime}$ region of the cDNA. The reverse NGS oligonucleotides also encode barcode sequences for multiplexing according to the TruSeq v1/v2/LT protocol (Illumina). The adaptors were added to the CDNA by PCR (8-14 cycles) using the long oligonucleotides (20-26) in $1 \mu \mathrm{M}$ stock solutions and the short amplifying oligos (18, 19) in $100 \mu \mathrm{M}$ stock concentration. PCR products were purified using a Qiagen PCR purification kit. The size and concentration of the fragments obtained were analyzed using a 2100 Agilent Bioanalyzer with the DNA 1000 kit.

\section{Preparation of $m R N A$ template library for NGS}

To prepare the mRNA library for NGS 5 pmol of mRNA was reverse transcribed using Superscript III (Invitrogen) using an NGS adapter $(27 / 28)$ containing a stretch of 18 nucleotides reverse complementary to the fixed "spacer" region in the 3 ' end of the mRNA. The resulting CDNA served as template for subsequent PCR using the forward (20) and reverse adapter (27/28) in $1 \mu \mathrm{M}$ stock concentration and the short amplifying oligonucleotides in $100 \mu \mathrm{M}$ stock concentration. PCR products were purified using a Qiagen PCR purification kit. The size and concentration of the fragments obtained were analyzed using a 2100 Agilent Bioanalyzer with the DNA 1000 kit.

\section{Next generation sequencing}

Next generation sequencing was performed by the Tufts Genomics Core Facility in Boston, USA on an Illumina HiSeq 2500 system in rapid run mode with $150 \mathrm{PE}$ read.

\section{Toeprinting}

Toeprinting to test novel arrest sequence motifs was performed using the PURExpress $\triangle R F-1,2,3$ kit (NEB). DNA templates were generated by PCR using T7_RBS_ATG_f, TP_3'_spacer_r and TP_NV1_r oligonucleotides (all at $1 \mu \mathrm{M}$ ) in combination with the oligonucleotide encoding the sequence to be tested. These oligonucleotides served as templates and were amplified using the T7_f and TP_NV1_r_short oligonucleotides $(100 \mu \mathrm{M})$ with Phusion DNA polymerase. PCR products were purified using the Qiagen PCR purification kit and eluted with $\mathrm{H}_{2} \mathrm{O}$ (molecular biology grade). Ery or Ole were dried into the tube to yield a final concentration of $50 \mu \mathrm{M}$ in the $5 \mu \mathrm{l}$ toeprinting reaction. $1 \mathrm{pmol}$ of DNA template was 
combined with $2 \mu \mathrm{l}$ of solution A and $1.5 \mu \mathrm{l}$ solution B of the PURExpress system. The reaction was incubated at $37^{\circ} \mathrm{C}$ for $15 \mathrm{~min}$ before addition of $1 \mu \mathrm{l}$ of the $5^{\prime}$-Yakima Yellow labeled NV1 probe (Vázquez-Laslop et al, 2008) (2 $\mu \mathrm{M})$ and the reaction was incubated for another $5 \mathrm{~min}$ at $37^{\circ} \mathrm{C}$. Reverse transcription was performed with $0.1 \mu \mathrm{l}$ dNTPS (10 mM stock of each dNTP), $0.4 \mu \mathrm{l}$ PURE system buffer, $0.5 \mu \mathrm{l} \mathrm{AMV} \mathrm{RT} \mathrm{(Promega),} \mathrm{and} 20 \mathrm{~min}$ incubation at $37^{\circ} \mathrm{C}$. After generation of the Yakima Yellow-labeled cDNA, the mRNA was degraded by addition of $0.5 \mu \mathrm{l} 10 \mathrm{M} \mathrm{NaOH}$ and incubation at $37^{\circ} \mathrm{C}$ for $20 \mathrm{~min}$. The samples were neutralized with $0.7 \mu \mathrm{l} 7.5 \mathrm{M} \mathrm{HCl} .20 \mu \mathrm{l}$ toeprint resuspension buffer (300 mM Na-acetate pH 5.5, $5 \mathrm{mM}$ EDTA, and $0.5 \%$ SDS) and $200 \mu \mathrm{l}$ PNI buffer were added to each sample and CDNA was purified using the Qiagen nucleotide removal kit. The cDNA was eluted using $50 \mu \mathrm{l}$ of $\mathrm{H}_{2} \mathrm{O}$ (molecular biology grade). cDNA was dried into the tube using a SpeedVac and resuspended in $6 \mu$ toeprint loading dye (95\% formamide, $250 \mu \mathrm{M}$ EDTA, and $0.25 \%$ bromophenol blue). Samples were denatured at $95^{\circ} \mathrm{C}$ for $5 \mathrm{~min}$ before loading onto a $7.5 \%$ polyacrylamide TBE sequencing gel containing $8 \mathrm{M}$ urea. The gel was run at $40 \mathrm{~W}$ and 2,000 V for $2.5 \mathrm{~h}$. Yakima-Yellow labeled cDNAs were detected using a Typhoon Gel Scanner in fluorescent mode.

\section{Disc diffusion assay}

We used the LacZ $\alpha$-based in vivo system described by Bailey et al (2008). Using oligonucleotides 39-50, we generated by PCR several plasmids in which we replaced the first 10 codons of the encoded ermCL with the sequence of interest, thus maintaining the regulatory region of erm CL and ermC. We transformed these plasmids into chemically competent $E$. coli TB1 cells. Transformants were grown for $6 \mathrm{~h}$ in LB media with $1 \mathrm{mM}$ IPTG at $37^{\circ} \mathrm{C}$ to an $\mathrm{OD}_{600}$ of 1.5 . For the MAXPW motifs, $50 \mu \mathrm{l}$ of IPTG (100 mM) were added to LB-agar plates containing ampicillin $(100 \mu \mathrm{g} / \mathrm{ml})$ and streptomycin $(50 \mu \mathrm{g} / \mathrm{ml})$ before the addition of $100 \mu \mathrm{l}$ cells. Whatman filter discs soaked with $10 \mu$ l 5-bromo-4-chloro-3-indolyl- $\beta$-D-galactopyranoside (X-gal) $(50 \mu \mathrm{M})$ and either water or $50 \mu \mathrm{g}$ Ery were placed onto the agar plates. For the ErmBL constructs, $50 \mu \mathrm{l}$ of IPTG (100 mM) and $50 \mu \mathrm{l}$ of $X$-gal $(50 \mu \mathrm{M})$ were added to LB-agar plates containing ampicillin $(100 \mu \mathrm{g} / \mathrm{ml})$ and streptomycin $(50 \mu \mathrm{g} / \mathrm{ml})$ before addition of $100 \mu \mathrm{l}$ cells. Whatman filter discs soaked with water or $50 \mu \mathrm{g}$ Ery or Ole were placed onto the agar plates. Agar plates were incubated at $37^{\circ} \mathrm{C}$ for $24 \mathrm{~h}$ and images were acquired immediately after the incubation period.

\section{Expression and purification of EF-P}

Expression of EF-P was performed together with the expression of the modification enzymes as described previously (Ude et al, 2013) in E. coli BL21 Gold, and expression was induced using 1 mM IPTG at an $\mathrm{OD}_{600}$ of 0.6. Harvested cells were resuspended in lysis buffer (50 mM Hepes- $\mathrm{KOH}, \mathrm{pH} 7.6,10 \mathrm{mM} \mathrm{MgCl}_{2}$, and $1 \mathrm{M} \mathrm{NH}_{4} \mathrm{Cl}$ ) and sonicated. Cell debris was removed by centrifugation ( $45 \mathrm{~min}$, $40,000 \mathrm{~g}, 4^{\circ} \mathrm{C}$ ) and the clarified lysate was mixed with cobaltagarose (Sigma-Aldrich) and incubated on a tube rotator at $4^{\circ} \mathrm{C}$ for $1 \mathrm{~h}$. The cobalt-agarose was washed with lysis buffer and the protein was eluted with lysis buffer containing $250 \mathrm{mM}$ imidazole. The eluate was concentrated using centrifugal concentrators with a MWCO of $10 \mathrm{kD}$ (Millipore). To exchange the buffer to protein storage buffer (20 mM Hepes- $\mathrm{KOH}$, pH 7.6, $10 \mathrm{mM} \mathrm{MgCl}$, $50 \mathrm{mM} \mathrm{KCl}$, and $50 \mathrm{mM} \mathrm{NH}_{4} \mathrm{Cl}$ ), gel filtration was performed through a Superdex 75 matrix using an NGC medium pressure liquid chromatography system (Bio-Rad). Eluate fractions were analyzed by SDS-PAGE and protein-containing fractions were pooled and concentrated to a final concentration of $20 \mathrm{mg} / \mathrm{ml}$ using centrifugal concentrators with a MWCO of $10 \mathrm{kD}$ (Millipore). The activity of the purified EF-P was assessed by toeprinting using a DNA template encoding the sequence MMHHHHHHRPPPI. Addition of EF-P to a final concentration of $10 \mu \mathrm{M}$ efficiently rescued ribosomes stalled on the polyproline motif.

\section{Data analysis}

Unless it is indicated otherwise, data analysis was carried out using a series of custom scripts written in-house in Python, which relied on the use of the Biopython package (Cock et al, 2009).

\section{Read assembly and trimming}

Read pairs were assembled using PEAR v0.9.10 (Zhang et al, 2014) on a Mac Book Pro with a $2.7 \mathrm{GHz}$ Intel Core i7 processor and 16 GB 1,600 $\mathrm{MHz}$ DDR3 memory, with the maximal proportion of uncalled bases in a read set to 0 (-u option) and the upper bound for the resulting quality score set to 126 (-c option).

Regions immediately upstream of the start codon and downstream of the point of cleavage by RNase $\mathrm{R}$ were removed using a modified version of the adaptor_trim.py script written by Brad Chapman (https://github. com/chapmanb/bcbb/blob/master/align/adaptor_trim.py). The 5' flanking region was defined as GTATAAGGAGGAAAAAAT, whereas the $3^{\prime}$ flanking region was GCGATCTCGGTGTGATG for the NNS $_{15}$ and ErmBL libraries, and GGTATCTCGGTGTGACTG for all other samples. A maximum of two mismatches within each of these flanking regions was tolerated, whereas all other reads were discarded. Trimming of the retained reads resulted in sequences with a start codon directly at the $5^{\prime}$ end and, in the case of samples resulting from inverse toeprinting, the site of RNase R cleavage at the $3^{\prime}$ end.

\section{Quality filtering and selection of the region of interest}

Trimmed sequences were further processed with our processreads.py script. Reads featuring $\geq 18$ " $A$ " bases within the first 22 nucleotides from the start codon were eliminated, as were reads from which the expected "ATG" start codon was absent. Sequences within the region of interest were retained for further analysis, provided that each base call within this region had a $Q$ score of 30 or more. For the $\mathrm{NNS}_{15}$ library sample, the region of interest spanned nucleotides $1-48$, where nucleotide 1 is the first nucleotide of the start codon. For all samples selected after translation of the $\mathrm{NNS}_{15}$ library, the region of interest is defined in Figs 1 and S7 and covered nucleotides 24-47. For all ErmBL-related samples, the region of interest covered nucleotides $30-32$ from the start codon. A summary of NGS read processing is given in Table S7.

\section{Analysis of RNase $R$ cleavage in known arrest sequences}

Assembled and trimmed reads for all of the known arrest sequences shown in Fig $1 \mathrm{~B}$ and $\mathrm{C}$ were processed using the processreads.py script, with the region of interest covering nucleotides 24-77 and the minimum $Q$ score for base calls within this region set 
to 60 . We then obtained the size distribution of reads that were exact matches to the $5^{\prime}$ end of each of the sequences in Table 58 . This task was automated with our find-exact-match.py script.

\section{Translation into amino acid sequences}

Processed reads were translated using the translate-reads.py script. For samples that had undergone inverse toeprinting, the ribosome-protected region downstream of the A-site codon was removed before translation. Unique peptidic sequences were identified and the frequency of occurrence of these sequences within each sample was calculated.

\section{Calculation of 3-aa motif frequencies}

All possible 3-aa motifs centered on the P-site of the stalled ribosomes were identified and counted within the translated sequences, using the process-kmers.py script with a word size of three. In each case, the frequency of occurrence $\left(F_{3 a a}\right)$ of the 3-aa motif was as follows:

$$
F_{3 a a}=\frac{n_{3 a a}}{n_{\text {total }}},
$$

where $n_{\text {заa }}$ is the number of occurrences of this 3-aa motif at the C-terminus of the translated sequences and $n_{\text {total }}$ is the total number of processed reads in the sample.

\section{Conversion into codon-based sequences}

Processed reads were converted to a codon-based sequence where each of the 64 possible codons was assigned a unique identifier, using the convert-to-codons.py script. For samples that had undergone inverse toeprinting, the ribosome-protected region downstream of the A-site codon was removed before translation. Unique codon-based sequences were identified and the frequency of occurrence of these sequences within each sample was calculated.

\section{Calculation of 3-codon motif frequencies}

All possible 3-codon motifs centered on the P-site codon of stalled ribosomes were identified and counted within the codon-based sequences, using the process-codon-kmers.py script with a word size of 3 codons. In each case, the frequency of occurrence $\left(F_{3 \text { codon }}\right)$ of the 3-codon motif was as follows:

$$
F_{3 \text { codon }}=\frac{n_{3 \text { codon }}}{n_{\text {total }}}
$$

where $n_{3 \text { codon }}$ is the number of occurrences of this 3 -codon motif at the C-terminus of the translated sequences, and $n_{\text {total }}$ is the total number of processed reads in the sample.

\section{Calculation of fold changes and propagation of inter-replicate errors}

The fold change in 3-aa or 3-codon motif frequency between two samples was calculated using the read-analyzer.py script and was defined as $F_{\mathrm{Fg}} / F_{\mathrm{Bg}}$, where $F_{\mathrm{Fg}}$ is the frequency of occurrence of a sequence, 3-aa or 3-aa motif in the "foreground" sample, and $F_{\mathrm{Bg}}$ is its frequency in the "background" sample. For the comparison between Ery-treated and untreated samples, the mean frequency of occurrence of each 3-aa motif in the presence or absence of the drug was as follows:

$$
F_{\text {Ery }}=\left(F_{\text {Ery1 }}+F_{\text {Ery2 } 2}\right) / 2 \text {, }
$$

and

$$
F_{\mathrm{NoAb}}=\left(F_{\mathrm{NoAb} 1}+F_{\mathrm{NoAb} 2}\right) / 2
$$

respectively.

Similarly, the errors between replicates were as follows

$$
\Delta F_{\text {Ery }}=\left|F_{\text {Ery1 }}-F_{\text {Ery2 }}\right| \text {, }
$$

and

$$
\Delta F_{\text {NoAb }}=\left|F_{\text {NoAb1 }}-F_{\text {NoAb2 }}\right| \text {. }
$$

The fold change in 3-aa motif frequency on addition of Ery was given as $F_{E r y} / F_{\text {NoAb }}$, and the combined error of the fold change in 3-aa frequency was as follows:

$$
\Delta\left(F_{\text {Ery }} / F_{\text {NoAb }}\right)=\sqrt{\left(\frac{\Delta F_{\text {NoAb }}}{F_{\text {NoAb }}}\right)^{2}+\left(\frac{\Delta F_{\text {Ery }}}{F_{\text {Ery }}}\right)^{2}} \times \frac{F_{\text {Ery }}}{F_{\text {NoAb }}},
$$

The histogram in Fig $3 \mathrm{~A}$ was built using the $\Delta\left(F_{\text {Ery }} / F_{\text {NoAb }}\right)$ values for all well-measured 3-aa motifs.

\section{Calculation of pause strengths}

Pause strengths for all 3-aa motifs were calculated using the calculate_all_pause_strengths.py script, according to the following formula:

$$
\text { Pause strength } \text { zaa }=\frac{n_{\mathrm{P}}}{n_{\mathrm{P}}+n_{\mathrm{B}}} \text {, }
$$

where $n_{p}$ is the number of reads where a ribosome is paused on the 3-aa motif of interest, and $n_{B}$ is the number of reads where the ribosome has translated through (bypassed) this motif.

\section{Data Deposition}

National Center for Biotechnology Information Short Read Archive: SRP140857.

\section{Supplementary Information}

Supplementary Information is available at https://doi.org/10.26508/lsa. 201800148

\section{Acknowledgments}

We thank A Malhotra for providing RNase R, N Vazquez-Laslop, and AS Mankin for providing the pERMZ $\alpha$ reporter plasmid, E. coli TB1 cells and oleandomycin, and AC Seefeldt for purifying fully modified EF-P. We thank A Buskirk for providing the pause scores for PP-containing motifs calculated from ribosome profiling data. CA Innis, B Seip, and G Sacheau received 
funding for this project from the European Research Council under the European Union's Horizon 2020 research and innovation program (grant agreement no. 724040). CA Innis is an EMBO YIP and the recipient of a Marie Curie career integration grant (PCIG14-GA-2013-631479). D Dupuy is funded by Inserm. B Seip, and CA Innis received funding from the Fondation pour la Recherche Médicale (AJE201133), the Région Aquitaine (2012-13-01-009), and a Chaire d'Installation from the excellence initiative (IdEX) of the University of Bordeaux.

\section{Author Contributions}

B Seip: Designed and performed experiments, analyzed data, drafted, reviewed and edited the manuscript.

G Sacheau: Performed experiments, analyzed data, reviewed and edited the manuscript.

D Dupuy: Designed experiments, analyzed data, drafted, reviewed and edited the manuscript.

CA Innis: Conceptualized and supervised the study, designed experiments, analyzed data, drafted, reviewed and edited the manuscript.

\section{Conflict of Interest Statement}

The authors declare that they have no conflict of interest.

\section{References}

Andrews SJ, Rothnagel JA (2014) Emerging evidence for functional peptides encoded by short open reading frames. Nat Rev Genet 15: 193. doi:10.1038/nrg3520

Arenz S, Bock LV, Graf M, Innis CA, Beckmann R, Grubmüller H, Vaiana AC, Wilson DN (2016) A combined cryo-EM and molecular dynamics approach reveals the mechanism of ErmBL-mediated translation arrest. Nat Commun 7: 12026. doi:10.1038/ncomms12026

Arenz S, Ramu H, Gupta P, Berninghausen O, Beckmann R, Vázquez-Laslop N, Mankin AS, Wilson DN (2014) Molecular basis for erythromycindependent ribosome stalling during translation of the ErmBL leader peptide. Nat Commun 5: 3501. doi:10.1038/ncomms4501

Bailey M, Chettiath T, Mankin AS (2008) Induction of erm(C) expression by noninducing antibiotics. Antimicrob Agents Chemother 52: 866-874. doi:10.1128/aac.01266-07

Chiba S, Lamsa A, Pogliano K (2009) A ribosome-nascent chain sensor of membrane protein biogenesis in Bacillus subtilis. EMBO I 28: 3461-3475. doi:10.1038/emboj.2009.280

Chiba Y, Ishikawa M, Kijima F, Tyson RH, Kim J, Yamamoto A, Nambara E, Leustek T, Wallsgrove RM, Naito S (1999) Evidence for autoregulation of cystathionine $\gamma$-synthase mRNA stability in Arabidopsis. Science 286: 1371-1374. doi:10.1126/science.286.5443.1371

Chiba Y, Sakurai R, Yoshino M, Ominato K, Ishikawa M, Onouchi H, Naito S (2003) S-adenosyl-L-methionine is an effector in the posttranscriptional autoregulation of the cystathionine $y$-synthase gene in Arabidopsis. Proc Natl Acad Sci USA 100: 10225-10230. doi:10.1073/pnas.1831512100

Cock PJ, Antao T, Chang JT, Chapman BA, Cox C), Dalke A, Friedberg I, Hamelryck T, Kauff F, Wilczynski B (2009) Biopython: Freely available Python tools for computational molecular biology and bioinformatics. Bioinformatics 25: 1422-1423. doi:10.1093/bioinformatics/btp163

Crooks GE, Hon G, Chandonia J-M, Brenner SE (2004) WebLogo: A sequence logo generator. Genome Res 14: 1188-1190. doi:10.1101/gr.849004
Davis AR, Gohara DW, Yap MN (2014) Sequence selectivity of macrolideinduced translational attenuation. Proc Natl Acad Sci USA 111: 15379-15384. doi:10.1073/pnas.1410356111

Dinos GP (2017) The macrolide antibiotic renaissance. Br J Pharmacol 174: 2967-2983. doi:10.1111/bph.13936

Ellington AD, Szostak JW (1990) In vitro selection of RNA molecules that bind specific ligands. Nature 346: 818. doi:10.1038/346818a0

Gong F, Ito K, Nakamura Y, Yanofsky C (2001) The mechanism of tryptophan induction of tryptophanase operon expression: Tryptophan inhibits release factor-mediated cleavage of TnaC-peptidyl-tRNAPro. Proc Natl Acad Sci USA 98: 8997-9001. doi:10.1073/pnas.171299298

Gupta P, Liu B, Klepacki D, Gupta V, Schulten K, Mankin AS, Vázquez-Laslop N (2016) Nascent peptide assists the ribosome in recognizing chemically distinct small molecules. Nat Chem Biol 12: 153. doi:10.1038/ nchembio.1998

Hartz D, MCPheeters DS, Gold L (1989) Selection of the initiator tRNA by Escherichia coli initiation factors. Genes Dev 3: 1899-1912. doi:10.1101/ gad.3.12a.1899

Horinouchi S, Weisblum B (1980) Posttranscriptional modification of mRNA conformation: Mechanism that regulates erythromycin-induced resistance. Proc Natl Acad Sci USA 77: 7079-7083. doi:10.1073/ pnas.77.12.7079

Ingolia NT, Brar GA, Rouskin S, McGeachy AM, Weissman JS (2012) The ribosome profiling strategy for monitoring translation in vivo by deep sequencing of ribosome-protected mRNA fragments. Nat Protoc 7 : 1534. doi:10.1038/nprot.2012.086

Ingolia NT, Ghaemmaghami S, Newman JRS, Weissman JS (2009) Genomewide analysis in vivo of translation with nucleotide resolution using ribosome profiling. Science 324: 218-223. doi:10.1126/science.1168978

Ito K (2014) Regulatory Nascent Polypeptides. Japan: Springer.

Ito K, Chiba S (2013) Arrest peptides: Cis-acting modulators of translation. Annu Rev Biochem 82: 171-202. doi:10.1146/annurev-biochem-080211-105026

Kannan K, Kanabar P, Schryer D, Florin T, Oh E, Bahroos N, Tenson T, Weissman JS, Mankin AS (2014) The general mode of translation inhibition by macrolide antibiotics. Proc Natl Acad Sci USA 111: 15958-15963. doi:10.1073/pnas.1417334111

Lu J, Deutsch C (2008) Electrostatics in the ribosomal tunnel modulate chain elongation rates. J Mol Biol 384: 73-86. doi:10.1016/j.jmb.2008.08.089

Luo Z, Sachs MS (1996) Role of an upstream open reading frame in mediating arginine-specific translational control in Neurospora crassa J Bacteriol 178: 2172-2177. doi:10.1128/jb.178.8.2172-2177.1996

Marks J, Kannan K, Roncase EJ, Klepacki D, Kefi A, Orelle C, Vázquez-Laslop N, Mankin AS (2016) Context-specific inhibition of translation by ribosomal antibiotics targeting the peptidyl transferase center. Proc Natl Acad Sci USA 113: 12150-12155. doi:10.1073/pnas.1613055113

Min YH, Kwon AR, Yoon EJ, Shim MJ, Choi EC (2008) Translational attenuation and mRNA stabilization as mechanisms of erm(B) induction by erythromycin. Antimicrob Agents Chemother 52: 1782-1789. doi:10.1128/aac.01376-07

Mohammad F, Woolstenhulme C), Green R, Buskirk AR (2016) Clarifying the translational pausing landscape in bacteria by ribosome profiling Cell Rep 14: 686-694. doi:10.1016/j.celrep.2015.12.073

Nakatogawa H, Ito K (2001) Secretion monitor, SecM, undergoes selftranslation arrest in the cytosol. Mol Cell 7: 185-192. doi:10.1016/s10972765(01)00166-6

Ndah E, Jonckheere V, Giess A, Valen E, Menschaert G, Van Damme P (2017) REPARATION: Ribosome profiling assisted (re-)annotation of bacterial genomes. Nucleic Acids Res 45: e168. doi:10.1093/nar/gkx758

O'Shea JP, Chou MF, Quader SA, Ryan JK, Church GM, Schwartz D (2013) pLogo: a probabilistic approach to visualizing sequence motifs. Nat Methods 10: 1211. doi:10.1038/nmeth.2646 
Orelle C, Szal T, Klepacki D, Shaw KJ, Vázquez-Laslop N, Mankin AS (2013) Identifying the targets of aminoacyl-tRNA synthetase inhibitors by primer extension inhibition. Nucleic Acids Res 41: e144. doi:10.1093/nar/gkt526

Peil L, Starosta AL, Lassak J, Atkinson GC, Virumäe K, Spitzer M, Tenson T, Jung K, Remme J, Wilson DN (2013) Distinct XPPX sequence motifs induce ribosome stalling, which is rescued by the translation elongation factor EF-P. Proc Natl Acad Sci USA 110: 15265-15270. doi:10.1073/ pnas. 1310642110

Qi F, Motz M, Jung K, Lassak J, Frishman D (2018) Evolutionary analysis of polyproline motifs in Escherichia coli reveals their regulatory role in translation. PLos Comp Biol 14: e1005987. doi:10.1371/journal. pcbi.1005987

Ramu H, Mankin A, Vazquez-Laslop N (2009) Programmed drug-dependent ribosome stalling. Mol Microbiol 71: 811-824. doi:10.1111/j.13652958.2008.06576.x

Ramu H, Vázquez-Laslop N, Klepacki D, Dai Q, Piccirilli J, Micura R, Mankin AS (2011) Nascent peptide in the ribosome exit tunnel affects functional properties of the A-site of the peptidyl transferase center. Mol Cell 41: 321-330. doi:10.1016/j.molcel.2010.12.031

Schneider TD, Stephens RM (1990) Sequence logos: A new way to display consensus sequences. Nucleic Acids Res 18: 6097-6100. doi:10.1093/ nar/18.20.6097

Scolnick E, Tompkins R, Caskey T, Nirenberg M (1968) Release factors differing in specificity for terminator codons. Proc Natl Acad Sci USA 61: 768-774. doi:10.1073/pnas.61.2.768

Seip B, Innis CA (2016) How widespread is metabolite sensing by ribosomearresting nascent peptides? J Mol Biol 428: 2217-2227. doi:10.1016/j. jmb.2016.04.019

Seiple IB, Zhang Z, Jakubec P, Langlois-Mercier A, Wright PM, Hog DT, Yabu K, Allu SR, Fukuzaki T, Carlsen PN, et al (2016) A platform for the discovery of new macrolide antibiotics. Nature 533: 338. doi:10.1038/nature17967

Shimizu Y, Inoue A, Tomari Y, Suzuki T, Yokogawa T, Nishikawa K, Ueda T (2001) Cell-free translation reconstituted with purified components. Nat Biotechnol 19: 751. doi:10.1038/90802

Sothiselvam S, Liu B, Han W, Ramu H, Klepacki D, Atkinson GC, Brauer A, Remm M, Tenson T, Schulten K, et al (2014) Macrolide antibiotics allosterically predispose the ribosome for translation arrest. Proc Natl Acad Sci USA 111: 9804-9809. doi:10.1073/pnas.1403586111

Storz G, Wolf YI, Ramamurthi KS (2014) Small proteins can no longer be ignored. Annu Rev Biochem 83: 753-777. doi:10.1146/annurevbiochem-070611-102400

Suzuki H, Zuo Y, Wang J, Zhang MQ, Malhotra A, Mayeda A (2006) Characterization of RNase R-digested cellular RNA source that consists of lariat and circular RNAs from pre-mRNA splicing. Nucleic Acids Res 34: e63. doi:10.1093/nar/gkl151
Tanner DR, Cariello DA, Woolstenhulme CJ, Broadbent MA, Buskirk AR (2009) Genetic identification of nascent peptides that induce ribosome stalling. J Biol Chem 284: 34809-34818. doi:10.1074/jbc.m109.039040

Tuerk C, Gold L (1990) Systematic evolution of ligands by exponential enrichment: RNA ligands to bacteriophage T4 DNA polymerase. Science 249: 505-510. doi:10.1126/science.2200121

Ude S, Lassak J, Starosta AL, Kraxenberger T, Wilson DN, Jung K (2013) Translation elongation factor EF-P alleviates ribosome stalling at polyproline stretches. Science 339: 82-85. doi:10.1126/science.1228985

Vázquez-Laslop N, Klepacki D, Mulhearn DC, Ramu H, Krasnykh O, Franzblau S, Mankin AS (2011) Role of antibiotic ligand in nascent peptidedependent ribosome stalling. Proc Natl Acad Sci USA 108: 10496-10501. doi:10.1073/pnas.1103474108

Vazquez-Laslop N, Thum C, Mankin AS (2008) Molecular mechanism of drugdependent ribosome stalling. Mol Cell 30: 190-202. doi:10.1016/j. molcel.2008.02.026

Vázquez-Laslop N, Ramu H, Klepacki D, Kannan K, Mankin AS (2010) The key function of a conserved and modified rRNA residue in the ribosomal response to the nascent peptide. EMBO J 29: 3108-3117. doi:10.1038/ emboj.2010.180

Vincent HA, Deutscher MP (2006) Substrate recognition and catalysis by the exoribonuclease RNase R. J Biol Chem 281: 29769-29775. doi:10.1074/ jbc.m606744200

Wilson DN, Arenz S, Beckmann R (2016) Translation regulation via nascent polypeptide-mediated ribosome stalling. Curr Opin Struct Biol 37: 123-133. doi:10.1016/j.sbi.2016.01.008

Wilson DN, Beckmann R (2011) The ribosomal tunnel as a functional environment for nascent polypeptide folding and translational stalling. Curr Opin Struct Biol 21: 274-282. doi:10.1016/j.sbi.2011.01.007

Woolstenhulme C), Guydosh NR, Green R, Buskirk AR (2015) High-precision analysis of translational pausing by ribosome profiling in bacteria lacking EFP. Cell Rep 11: 13-21. doi:10.1016/j.celrep.2015.03.014

Woolstenhulme CJ, Parajuli S, Healey DW, Valverde DP, Petersen EN, Starosta AL, Guydosh NR, Johnson WE, Wilson DN, Buskirk AR (2013) Nascent peptides that block protein synthesis in bacteria. Proc Natl Acad Sci USA 110: E878-E887. doi:10.1073/pnas.1219536110

Zhang J, Kobert K, Flouri T, Stamatakis A (2014) PEAR: A fast and accurate Illumina paired-end reAd mergeR. Bioinformatics 30: 614-620. doi:10.1093/ bioinformatics/btt593

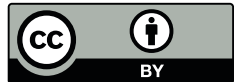

License: This article is available under a Creative Commons License (Attribution 4.0 International, as described at https://creativecommons.org/ licenses/by/4.0/). 